Research Article

\title{
Nephroprotective effect of ethanolic extract of abutilon indicum root in gentamicin induced acute renal failure
}

\author{
Jacob Jesurun RS*, Lavakumar S.
}

Department of Pharmacology, Sri Sathya Sai Medical College, Ammapet, Kanchipuram District, Tamilnadu, India

Received: 03 March 2016 Accepted: 04 April 2016

\section{*Correspondence to:}

Dr. Jacob Jesurun RS, Email: drrsjj@gmail.com

Copyright: (C) the author(s), publisher and licensee Medip Academy. This is an openaccess article distributed under the terms of the Creative Commons Attribution NonCommercial License, which permits unrestricted noncommercial use, distribution, and reproduction in any medium, provided the original work is properly cited.

\begin{abstract}
Background: The term acute renal failure (ARF) is at present called acute kidney injury (AKI). AKI is a reversible condition in which there is a sudden decline in renal function, manifested by elevated SCr and BUN which occurs in hours to days to weeks. The present study was to evaluate the nephron protective effect of abutilon indicum root in gentamicin induced acute renal failure in wistar albino rats.

Methods: Experimental evaluation was done in gentamicin induced acute renal failure. 24 rats were divided into 6 in each group. Group 1 was given normal saline $(10 \mathrm{ml} / \mathrm{kg})$ per oral, group 2 with gentamicin $(100 \mathrm{mg} / \mathrm{kg}$, ip for 5 days), group 3 with gentamicin and extract $150 \mathrm{mg} / \mathrm{kg}$ and, group 4, gentamicin and extract $300 \mathrm{mg} / \mathrm{kg}$ and group 5, extract $300 \mathrm{mg} / \mathrm{kg}$. The dose of the extract was given orally $60 \mathrm{~min}$ prior to gentamicin injection. The duration of the study was for 7 days all the doses are given once a day for 7 days. 24 urine output, serum creatinine ( $\mathrm{SCr}$ ), blood urea nitrogen (BUN), total proteins and albumin were measured at end of the day for all the groups. Kidneys were examined for histopathological changes.

Results: Animals treated with extract showed significant improvement in biochemical parameters and histopathological changes compared to group II animal as treated with gentamicin. The protective effect was highly significant the dose of $300 \mathrm{mg} / \mathrm{kg}$ of extract.

Conclusions: The ethanolic extract of abutilon indicum root has nephron protective effect in gentamicin induced acute renal failure. Nephro protective action in this study could be due to the antioxidant and other phytochemical of abutilon indicum root.
\end{abstract}

Keywords: Abutilon indicum root, Renal failure, Nephro protective, Gentamicin

\section{INTRODUCTION}

The term acute renal failure (ARF) is at present called acute kidney injury (AKI). AKI is a reversible condition in which there is a sudden decline in renal function, manifested by elevated SCr and BUN which occurs in hours to days to weeks. ${ }^{1}$

Acute kidney injury is associated with increased mortality and morbidity in undeveloped and developing countries. Acute kidney injury previously termed as acute renal failure (ARF) is reversible condition where there is an abrupt decline in renal function, manifested by acute elevation in plasma blood urea nitrogen (BUN) and serum creatinine, occurring in hours to days to weeks. ${ }^{2}$

\begin{abstract}
AKI is defined as per kidney disease improving global outcome (KDIGO) clinical practice guidelines, AKI is any of the following increase in serum creatinine $(\mathrm{sCr})$ by $\geq 0.3 \mathrm{mg} / \mathrm{dl}(\geq 26.5 \mathrm{umol} / \mathrm{l})$ within 48 hours; or an increase in serum creatinine to $\geq 1.5$ times baseline, which is known or presumed to have occurred within the preceding 7 days; or a urine volume $<0.5 \mathrm{ml} / \mathrm{kg} / \mathrm{h}$ for 6 hours. ${ }^{3}$
\end{abstract}

The incidence of AKI is 2,147 and 4,085 per million populations per year (pmp) in developing and developed countries respectively. 4,5 
Recent reports in the developed world indicate that AKI is seen in $3.2-9.6 \%$ of hospital admissions with overall mortality of $20 \%$ to $50 \%$ in ICU patients. ${ }^{6,7}$

AKI demanding renal replacement therapy is 5-6\% with a high in-hospital mortality rate of $60 \%$. It is estimated that nearly 2 million people die of AKI every year globally.,

Hence, anticipation of AKI should be given the priority. Management of renal failure includes: withdrawal of the medications causing ARF, treatment of the cause, correction of electrolyte and fluid imbalance, diuresis, dialysis, renal replacement therapy.

As the cost of lifelong dialysis/renal transplantation is not affordable for majority of the Indian population, an alternative equally effective lifesaving therapy is mandatory to save these patients. In this context evaluation of traditional medicinal plants which are reported effective in renal failure is a necessity. There are many plants have been screened for nephro protective activity both in acute and chronic renal failure models in India. ${ }^{10,11}$ Abutilon indicum is belongs to malvaceae family. It has been used for commonly called 'Country mallow' is a perennial plant up to $3 \mathrm{~m}$ in height. Abutilon indicum abundantly found as a weed in the subHimalayan tract and in the hotter parts of India. A. indicum is reported to have hypoglycemic, hepatoprotective, antimicrobial, male contraceptive and antidiarrheal activities. $^{12}$

Hence, this study was to evaluate the effect of ethanolic extract of abutilon indicum root in getamicin induced acute renal failure in wistar albino rats its action in animal models of renal failure.

\section{METHODS}

The study was initiated after getting IAEC (institutional animal ethics committee) approval Lr.02/02/2015.

All chemicals were purchased from sigma Aldrich New Delhi, India.

\section{Animals}

Male wistar albino rats, body weight ranging from 160$200 \mathrm{~g}$ bred in the animals were procured from, The king institute of preventive medicine, Guindy, Chennai-32, India. They were kept at room temperature and were maintained ad libitum on tap water and growers mash except in the last 15 hours before termination of the experiment. The animals were housed in plastic cages under conditions of 12 hours light/12 hours dark cycle.

\section{Experimental design}

42 wistar albino rats were used, 12 rats for acute toxicity study and 30 rate for acute renal failure.

\section{Acute toxicity study}

Acute oral toxicity study was conducted as per OECD 423 guidelines to assess the safety and determine the dose. $^{13}$

\section{$A R F$}

ARF was induced by intra muscular injection of gentamicin dose $100 \mathrm{mg} / \mathrm{kg}$, ip for 5 days. ${ }^{14}$

Animals were divided into five groups of six animals in each group.

Table 1: Group of animals.

\begin{tabular}{|ll|}
\hline Animals & Treatment \\
\hline Group -1 & Control - normal saline $(10 \mathrm{ml} / \mathrm{kg})$. \\
\hline Group -2 & Gentamicin $(100 \mathrm{mg} / \mathrm{kg}, \mathrm{ip})$ \\
\hline Group -3 & Gentamicin+extract $150 \mathrm{mg} / \mathrm{kg}$. \\
\hline Group -4 & Gentamicin+extract $300 \mathrm{mg} / \mathrm{kg}$. \\
\hline Group -5 & Extract $300 \mathrm{mg} / \mathrm{kg}$ alone. \\
\hline
\end{tabular}

The extract was given by oral route 60 minutes prior to the gentamicin injection. The animals were observed for general behaviour and activity. Urine output was measured for all animals for 24 hours. ${ }^{15}$

End of the blood samples were collected by retro-orbital sinus puncture under halothane anesthesia. ${ }^{16}$ To assess the renal function following biochemical parameters were tested serum creatinine, blood urea nitrogen, total proteins and albumin. ${ }^{17-20}$

Immediately after taking blood samples, the animals were sacrificed using high dose of halothane. After euthanasia kidneys were harvested from all the groups and sent for histopathology studies.

\section{Statistical analysis}

The data were expressed as Mean \pm SEM One way ANOVA followed by Dunnett's post hoc test was applied to calculate the statistical significance among different groups. $\mathrm{P}<0.05$ was considered to be statistically significant.

\section{RESULTS}

\section{Acute toxicity study}

Acute toxicity study was carried out according to OECD guide lines. No mortality or toxicity was observed up to $5000 \mathrm{mg} / \mathrm{kg}$. Hence, extract was found to be safe.

\section{Nephro protective activity in ARF}

Increased levels of serum creatinine, blood urea nitrogen and decreased total proteins, albumin and urine output in 
glycerol treated animals was seen (group-2) compared with normal saline treated animals (group-1). In extract treated groups there was a significant reduction $(\mathrm{p}<0.05)$ in serum creatinine, blood urea nitrogen and an increase in total proteins, albumin and urine output at both the doses of 150 and $300 \mathrm{mg} / \mathrm{kg}$. The effect was better with $300 \mathrm{mg} / \mathrm{kg}$. The group treated with root extract alone (group-5) did not show any change in the above parameters (Figure 1-5).

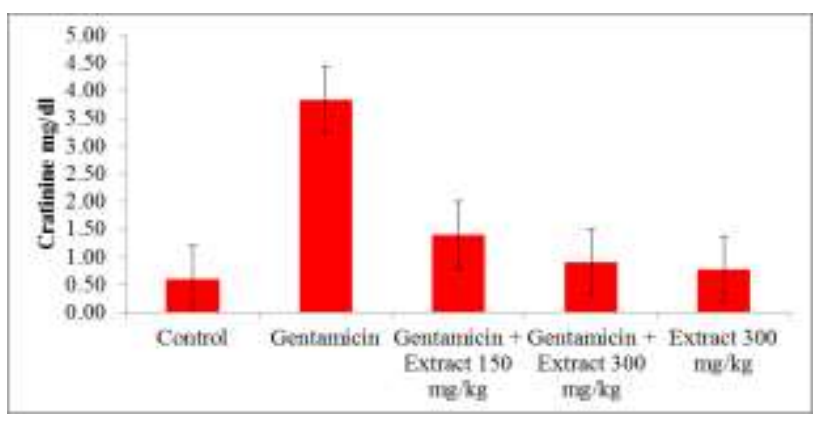

Figure 1: Serum creatinine.

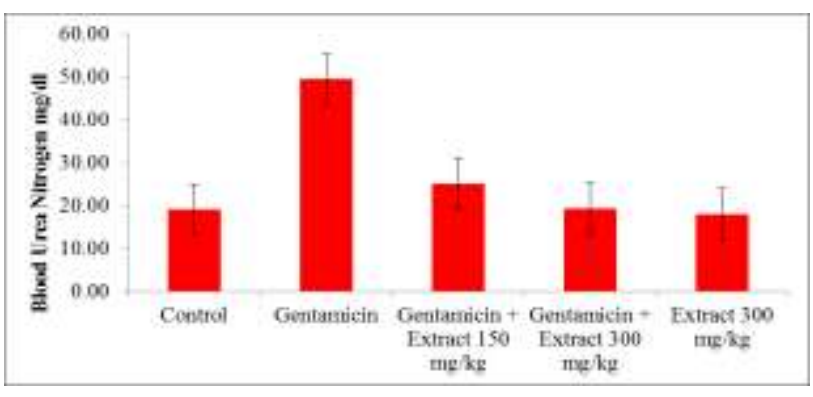

Figure 2: Blood urea nitrogen mg/dl.

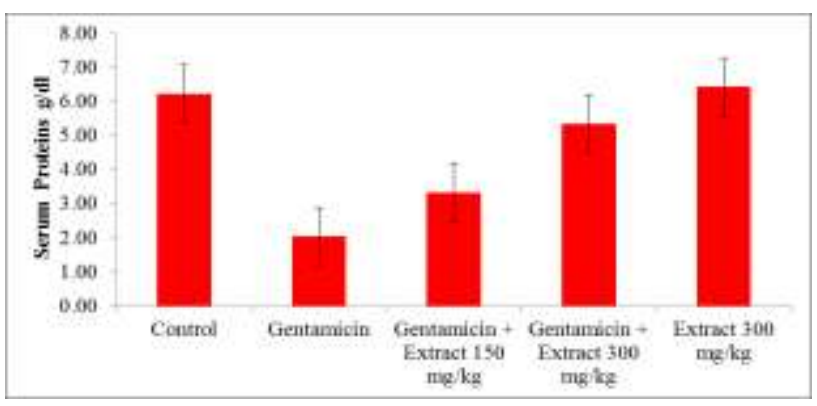

Figure 3: Serum total proteins g/dl.

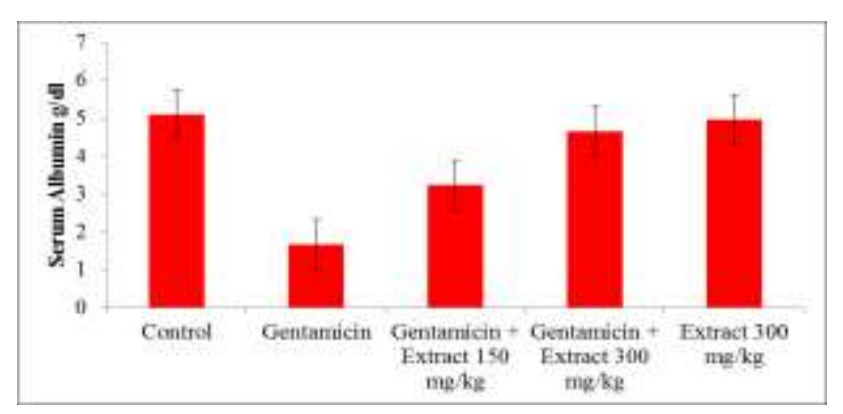

Figure 4: Serum albumin g/dl.

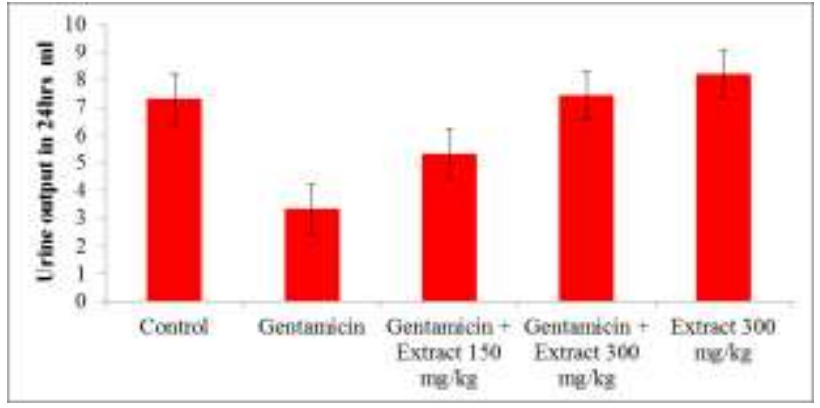

Figure 5: Urine output in 24 hours ml.

\section{Histopathology of kidney}

Rat kidney had shown normal glomeruli with intact Bowman's capsule, normal proximal convoluted and distal convoluted tubules and there was no capillary congestion or haemorrhage in group 1. In group-2, severe distortion of glomeruli, haemorrhagic, capillary congestion and apical blebbing were seen. In group 3 and 4, treated with 150 and $300 \mathrm{mg} \mathrm{kg}$ of plant extract showed markedly reduced capillary congestion, tubular damage, and glomerular distortion compared to group-2. The protective effect was found to be better with $300 \mathrm{mg} / \mathrm{kg}$ than $150 \mathrm{mg} / \mathrm{kg}$. Group-5 animals were not sacrificed as they did not show abnormalities in biochemical parameters. The histopathological changes were found to be in correlation with biochemical changes (Figure 6).
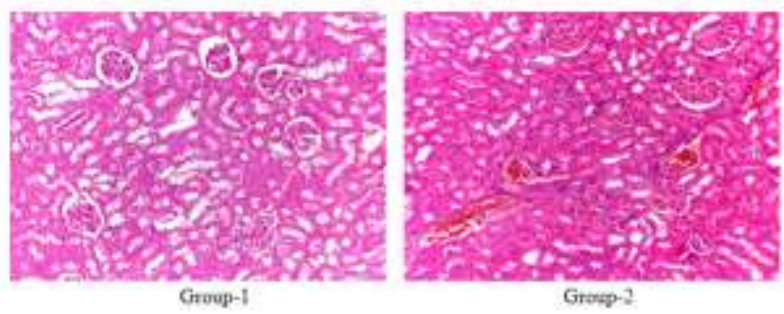



Gtoap-3

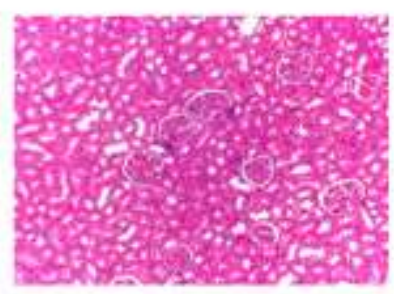

Group-4
Figure 6: (Histopathology) kidneys were stained with haematoxylin and eosin and figures were in $10 x$ magnification.

\section{DISCUSSION}

Renal failure acute or chronic causes severe morbidity and sometimes mortality. The current treatment includes management of the cause and supportive measures. The medical management though helps the subjects and prolongs life most often it fails and patients have to be on renal replacement therapy. Renal dialysis has saved the 
lives of many patients with renal failure. But, the cost involved the frequency of dialysis and the discomfort and the compromise on the quality of life experienced by the subjects make them opt for alternative systems of therapy.

In traditional systems different medicinal plants are used with the claim of cure for renal failure.

The present study has evaluated the effect of ethanolic extract of abutilon indicum root in gentamicin induced acute renal failure.

Gentamicin is one of the most commonly using aminoglycoside antimicrobial drugs among antibiotics. Several risk factors associated with aminoglycoside nephrotoxicity have been identified in humans and experimental animals. They include an initial high rate of creatinine clearance, high initial peak levels in serum nitrogen, age, sex, and duration of therapy, liver disease, and renal infection. The concomitant administration of steroids has never been investigated. ${ }^{21}$ This was supported by proximal tubular histology suggestive of gross tubular damage. These observations were similar the report of Ali who reported similar biochemical and histological changes suggestive of nephrotoxicity. ${ }^{22}$ It has been suggested that the oxidative stress induces tubular damage. $^{23}$

In our study ARF was induced by intra peritoneal injection of gentamicin dose $100 \mathrm{mg} / \mathrm{kg}$, ip for 5 days. The biochemical parameters are serum creatinine and blood urea nitrogen were significantly increased and albumin, total proteins and urine output were significantly reduced in gentamicin treated animals (group-2)

Treatment with extract 150 and $300 \mathrm{mg} / \mathrm{kg}$ shown significantly improved all the parameters compared with gentamicin treated animals.

The histopathological examination had shown several ruptured glomeruli, undefined proximal, distal convoluted tubules, interstitial damage, capillary congestion and haemorrhages in untreated group, whereas in animals treated with plant extract these changes have been markedly reduced.

The findings suggest that protection from oxidative damage, anti-inflammatory and vasodilatory activities could be the mechanisms for the nephro protective actions of abutilon indicum root in acute renal failure. Between the 2 doses administered, 150 and $300 \mathrm{mg} / \mathrm{kg}, 300 \mathrm{mg} / \mathrm{kg}$ is found to have significant nephro protective action.

\section{CONCLUSION}

The plant extract was found to have pre-treatment with 2 doses of extract, 150 and $300 \mathrm{mg} / \mathrm{kg}$, exhibited protective effect ARF. Serum creatinine and BUN were reduced whereas urine output, serum total proteins and albumin were increased and histopathology of kidney was improved with plant extract treatment. These findings confirm the nephro protective effect of abutilon indicum root in animal model of ARF. The nephro protection was better with $300 \mathrm{mg} / \mathrm{kg}$ of abutilon indicum root than 150 $\mathrm{mg} / \mathrm{kg}$. Nephro prtoective effect could be due to its antioxidant and anti-inflammatory of abutilon indicum root.

Funding: Sri Sathya Sai Medical College and Research Institute of Medical Colllege

Conflict of interest: None declared

Ethical approval: The study was approved by the Institutional Ethics Committee

\section{REFERENCES}

1. Schrier R, Wang W, Poole B, Mitra A. Acute renal failure: definitions, diagnosis, pathogenesis, and therapy. Journal of Clinical Investigation. 2004;114(4):598-8.

2. Nissenson AR. Acute renal failure: definition and pathogenesis. Kidney Int Suppl. 1998;66:7-10.

3. Khwaja A. KDIGO clinical practice guidelines for acute kidney injury. Nephron Clin Pract. 2012;120:179-84.

4. Ali T, Khan I, Simpson W, Prescott G, Townend J, Smith $\mathrm{W}$, et al. Incidence and outcomes in acute kidney injury: a comprehensive population-based study. J Am Soc Nephrol. 2007;18:1292-8.

5. Hsu C, McCulloch C, Fan D, Ordonez J, Chertow G, Go A. Community-based incidence of acute renal failure. Kidney Int. 2007;72:208-12.

6. Fang Y, Ding X, Zhong Y, Zou J, Teng J, Tang Y, et al. Acute kidney injury in a chinese hospitalized population. Blood Purif. 2010;30:120-6.

7. Lafrance J, Miller D. Acute kidney injury associates with increased long-term mortality. J Am Soc Nephrol. 2010;21:345-52.

8. Uchino S, Bellomo R, Morimatsu H, Morgera S, Schetz M, Tan I, et al. Continuous renal replacement therapy: a worldwide practice survey. Intensive Care Med. 2007;33:1563-70.

9. Murugan R, Kellum J. Acute kidney injury: what's the prognosis? Nat Rev Nephrol. 2011;7:209-17.

10. Bharti DT, Raghunath TM, Manojkumar ZC, Namrata VN. Nephroprotective plants: a review. Int J Pharm Pharm Sci. 2012;1:8-16.

11. Konda VR, Arunachalam R, Eerike M, Rao R, Radhakrishnan AK, Raghuraman LP, et al. Nephroprotective effect of ethanolic extract of Azima tetracantha root in glycerol induced acute renal failure in wistar albino rats. Journal of Traditional and Complementary Medicine. 2015;(6):1-8.

12. Goyal N, Singh S, Sharma SK, Analgesic effects of various extracts of the root of Abutilon indicum linn. 2009;(1)43-6.

13. OECD Guidelines for the testing of chemicals (No 423) acute oral toxicity-acute toxic class method.

14. Erdem A, Gundogan NU, Usubutun A, Kilinc K, Erdem SR, Kara A, Bozkurt A: the protective effect 
of taurine against gentamicin-induced acute tubular necrosis in rats. Nephrol Dial Transplant. 2000; $15: 1175-82$.

15. Kurien BT, Everds NE, Scofield RH. Experimental animal urine collection: a review. Laboratory Animals. 2004;38:333-61.

16. Parasuraman S, Raveendran R, Kesavan R. Blood sample collection in small laboratory animals. J Pharmacol Pharmacother. 2010;1(2):87-93.

17. Chromy V, Rozkosna K, Sedlak P. Determination of serum creatinine by Jaffe method and how to calibrate to eliminate matrix interference problems. Clin Chem Lab Med. 2008;46:1127-33.

18. Kabeya T, Ohkura Y. A new colorimetric method for the determination of urea nitrogen in blood with diacetyl monoxime glucuronolactone glucosaccharodilactone reagent. Chem Pharm Bull. 1972;20(4):837-9.
19. Doumas BT, Bayse DD, Carter RJ, Peters T, Schaffer R. A candidate reference method for determination of total protein in serum. I Development and validation. Clin Chem. 1981;27(10):1642-50.

20. Affonso A, Lasky F. Bromocresol purple dye-binding method for the estimation of serum albumin adapted to the SMA 12/60. Clinical Biochemistry. 1985;18(5):285-9.

21. Beauchamp DE, Pettigrew MA. Influence of hydrocortisone on gentamicin-induced nephrotoxicity in rats. Antimicrobial agents and chemotherapy. 19881;32(7):992-6.

22. Ali BH. The effect of Nigella sativa oil on gentamicin nephrotoxicity in rats. The American journal of Chinese medicine. 2004;32(01):49-55.

23. Cuzzocrea S, Mazzon E, Dugo L, Serraino I, Di Paola R, Britti D, et al. A role for superoxide in gentamicin-mediated nephropathy in rats. European journal of pharmacology. 2002;450(1):67-76.

Cite this article as: Jacob Jesurun RS,

Lavakumar S. Nephroprotective effect of ethanolic extract of abutilon indicum root in gentamicin induced acute renal failure. Int J Basic Clin Pharmacol 2016;5:841-5. 